\title{
Inhibition of oocyte growth factors in vivo modulates ovarian folliculogenesis in neonatal and immature mice
}

\author{
Samu Myllymaa ${ }^{1,2}$, Arja Pasternack ${ }^{1,2,6}$, David G Mottershead ${ }^{1,2}$, Matti Poutanen ${ }^{3,4}$, \\ Minna M Pulkki ${ }^{1,2}$, Lauri J Pelliniemi ${ }^{5}$, Olli Ritvos ${ }^{1,2}$ and Mika P E Laitinen ${ }^{1,2,6}$ \\ ${ }^{1}$ Department of Bacteriology and Immunology, Haartman Institute, University of Helsinki, PO Box 21, Fl-00014 \\ Helsinki, Finland, ${ }^{2}$ HUSLAB, Helsinki University Central Hospital, FI-00029 Helsinki, Finland, ${ }^{3}$ Department of \\ Physiology, Institute of Biomedicine, ${ }^{4}$ Turku Center for Disease Modeling and ${ }^{5}$ Laboratory of Electron Microscopy, \\ University of Turku, Fl-20520 Turku, Finland and ${ }^{6}$ Biotechvisions Ltd, Tukholmankatu 8B, FIN-00270 \\ Helsinki, Finland
}

Correspondence should be addressed to S Myllymaa at Department of Bacteriology and Immunology, Haartman Institute, University of Helsinki; Email: samu.myllymaa@helsinki.fi

D G Mottershead is now at School of Paediatrics and Reproductive Health, Medical School, Robinson Institute, University of Adelaide, Adelaide 5005, South Australia, Australia

M M Pulkki is now at Vactech Oy, Biokatu 8, FIN-33520 Tampere, Finland

\begin{abstract}
Growth differentiation factor-9 (GDF9) and bone morphogenetic protein-15 (BMP15) are among the key regulators transmitting the signaling between the oocyte and the surrounding granulosa cells. Previously, it has been shown that a recombinant BMP type II receptor ectodomain-Fc fusion protein (BMPR2ecd-Fc) is able to inhibit the actions of GDF9 and BMP15 in vitro. Here, we have produced bioactive BMPR2ecd-Fc, which was injected i.p. into neonatal mice. Early folliculogenesis was first studied by injecting mice five times with various doses of BMPR2ecd-Fc during the postnatal days 4-12. Folliculogenesis was affected dose dependently, as evidenced by a decreased mitogenesis of granulosa cells of the growing follicles. Furthermore, we also noticed a decrease in the number of secondary and tertiary follicles as well as an increase in the oocyte size. Electron microscopic analysis revealed that the ultrastructure of the granulosa cells of the primary follicles was not affected by the BMPR2ecd-Fc treatment. A second study was conducted to investigate whether a longer treatment with 12 injections during postnatal days 4-28 would inhibit folliculogenesis. Similar effects were observed in the two studies on the early follicular developmental stages. However, in the long-term study, later stages of folliculogenesis were not blocked but rather increased numbers of antral follicles, preovulatory follicles, and corpora lutea were found. We conclude that BMPR2ecd-Fc is a potent modulator of ovarian folliculogenesis in vivo, and thus, is a valuable tool for studying the physiology and downstream effects of oocyte-derived growth factors in vivo.

Reproduction (2010) 139 587-598
\end{abstract}

\section{Introduction}

Mammalian folliculogenesis can be divided into three developmental stages. Primordial stage of follicles can be considered as a storage depot for the female gametes. The preantral stage is a development phase which is strongly regulated by paracrine signals, without extraovarian hormonal stimuli. By the preantral stage, the follicle's structure is formed and the granulosa and theca cells are able to support the process of opening of the antral cavity, which characterizes the beginning of the antral stage, which allows further maturation of the oocyte and ultimately the release of fertilizable eggs. The basis of early folliculogenesis and its key players is well reviewed by Hutt \& Albertini (2007).
Transforming growth factor $\beta$ (TGFB) superfamily members have been recently recognized among the key regulators of early folliculogenesis. They mediate their primary actions through serine/threonine kinase receptors, and their downstream targets have been studied extensively. Factors that control the primordial and preantral phases of folliculogenesis have been shown to be essential for normal folliculogenesis, as reviewed comprehensively by Knight \& Glister (2006). Granulosa cell-derived anti-Müllerian hormone (also known as Müllerian inhibiting substance) inhibits the activation of primordial follicle growth in the mouse ovary (Durlinger et al. 2002). Very recently, oocytespecific deletion of phosphatase and tensin homolog 
deleted on chromosome 10 was shown to cause a premature activation of the entire primordial follicle pool, ultimately resulting in premature ovarian failure (POF; Reddy et al. 2008). c-Kit and its ligand (KL, also called stem cell factor) are also required for normal folliculogenesis (Packer et al. 1994, Klinger \& de Felici 2002). KL is suggested to be regulated by the oocyte-derived growth factors, growth differentiation factor 9 (GDF9) and bone morphogenetic protein-15 (BMP15, also known as GDF9B) in a specific manner. GDF9 suppresses KL expression in mouse preantral granulosa cells, whereas in bovine antral granulosa cell culture, GDF9 increases KL transcript levels ( Joyce et al. 2000, Nilsson \& Skinner 2002). Moreover, BMP15 stimulates $K L$ expression in rat antral granulosa cells, while $\mathrm{KL}$ is able to negatively regulate BMP15 transcripts in a paracrine manner (Otsuka \& Shimasaki 2002). In GDF9-deficient mice, KL is upregulated (Elvin et al. 1999). In addition, numerous TGFB superfamily members are known to control ovarian regulation mechanisms such as luteinization, follicle survival, and developmental competence, as well to have a role in cross-talk between $\mathrm{FSH}$-, epidermal growth factor-, and insulin-like growth factor-mediated signaling pathways (Knight \& Glister 2006).

Oocyte-derived GDF9 (McPherron \& Lee 1993) and BMP15 (Laitinen et al. 1998) act upon granulosa cells to control their proliferation and differentiation, thus contributing to the formation of the follicle's structure. GDF9 has been shown to be essential for folliculogenesis to progress beyond the primary stage in mice (Carabatsos et al. 1998). In women, GDF9 has been suggested to play a role in POF and polycystic ovarian syndrome (Teixeira Filho et al. 2002, Chand et al. 2006, Laissue et al. 2006, Kovanci et al. 2007), and to have a role in twinning (Montgomery et al. 2004, Palmer et al. 2006). In sheep, GDF9 is required for follicles to develop beyond the secondary stage, and also GDF9 has an effect on ovulation rate (McNatty et al. 2006). In addition, mutations in BMP15 have been shown to have dose-dependent phenotypes ultimately resulting in either increased ovulation or infertility in sheep (Galloway et al. 2000). More drastic disruption of BMP15 signaling caused hypergonadotropic ovarian failure in women (Di Pasquale et al. 2004). However, BMP15 knockout mice suffer only from subfertility and usually have minimal ovarian histopathological defects (Yan et al. 2001). These studies emphasize the fact that these two factors have different functions in the ovary and exhibit species-specific roles. GDF9 and BMP15 are also known to synergize while mediating paracrine signaling (Yan et al. 2001, McNatty et al. 2005a, 2005b). They also cooperate with other growth factors (Sugiura et al. 2007), and play a role in cholesterol biosynthesis (Su et al. 2008).

In recent years, the signaling pathways utilized by GDF9 and BMP15 have began to be illuminated. GDF9 activates the TGFB-type signaling pathway by using the activin receptor-like kinase-5 (ALK5; Mazerbourg et al.
2004, Kaivo-Oja et al. 2005) and BMP type II receptor (BMPR2; Vitt et al. 2002). Cooperative signaling by GDF9 and BMP15 is also mediated through BMPR2 (Edwards et al. 2007). BMP15 utilizes the ALK6 and the BMP pathway (SMAD1/5/8) to mediate responses (Moore et al. 2003). GDF9 primarily utilizes the SMAD2/ 3 pathway to mediate its intracellular responses (Kaivo-Oja et al. 2003, 2005, Roh et al. 2003, Mazerbourg et al. 2004, Mottershead et al. 2008). Interestingly, normal folliculogenesis requires SMAD3, which was demonstrated in SMAD3-deficient mice (Tomic et al. 2004). The SMAD2/3 pathway has been shown to be the primary pathway for paracrine actions to modulate granulosa cell proliferation in oocyte cultures, and it could be interrupted by the BMPR2ecd-Fc molecule (Gilchrist et al. 2006). This pathway is also essential for cumulus expansion (Dragovic et al. 2007). It has recently been shown that larger follicles express higher levels of BMPR2 than smaller follicles, and that the expression of BMPR2 is regulated by $\mathrm{FSH}$ and estradiol in ovine granulosa cells (Chen et al. 2008).

It is now well established that paracrine signaling is essential for the balance of ovarian functions, and that BMPR2 is the key receptor for the transmission of the actions of the oocyte-secreted factors GDF9 and BMP15 in vitro. High-resolution structures of BMPR2 reveal a similarity with activin type II receptor (ActRII), which is no surprise, since they have overlapping ligand specificity. BMPR2 has the basic three-finger toxin fold and hydrophobic patch used by ActRII to bind various ligands (Mace et al. 2006). Since the onset of Fc fusion molecule development at the beginning of 1990s, numerous therapeutic applications have been developed, and the versatility of the Fc fusion molecules has become apparent (Chamow \& Ashkenazi 1996).

In this study, we evaluated whether repeated injections of the recombinant BMPR2ecd-Fc fusion protein and an anti-GDF9 MAB \#37, which was described previously (Gilchrist etal. 2004), would affect mouse folliculogenesis. We produced and purified a recombinant BMPR2ecd-Fc fusion protein and evaluated its biological activity in vitro. This was followed by testing how the fusion protein would affect ovarian folliculogenesis dose dependently in the short-term study. Furthermore, we wanted to know whether a long-term injection scheme would result in a shutdown of the ovary or whether BMPR2ecd-Fc has an effect on later follicular stages and ovulation.

\section{Results \\ Purification and bioactivity testing of the BMPR2ecd-Fc fusion protein}

The recombinant BMPR2ecd-Fc fusion protein was purified to over $95 \%$ purity by using immobilized metal affinity chromatography (Fig. 1A), after which the purified protein was tested for its bioactivity to inhibit 

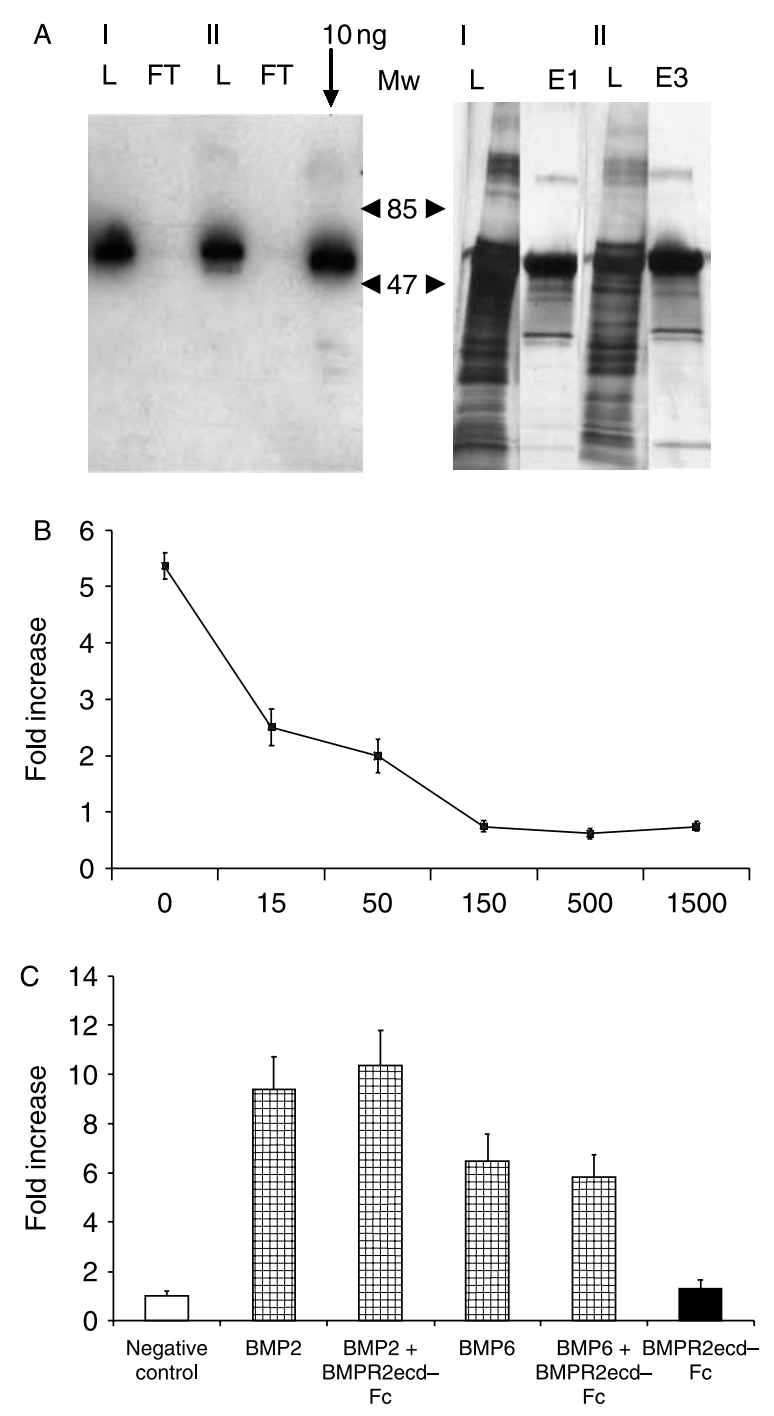

Figure 1 Production and purification and bioactivity analysis of BMPR2ecd-Fc protein. (A) On the left, a western blot showing production media from $\mathrm{CHO} / \mathrm{BMPR} 2 \mathrm{ecd}-\mathrm{Fc}$ cell line (L), flow-through from the purification (FT), 10 ng of purified BMPR2ecd-Fc and molecular weight marker ( $\mathrm{Mw}$, in thousands). On the right, silver gel illustrating the load-in (L) and elution fractions from the purification (E1 and E3, separate purifications marked with roman numerals I and II). No recombinant protein was detected in FT, confirming the effective collection of the BMPR2ecd-Fc onto the resin. (B) Dose-dependent effect of the BMPR2ecd-Fc fusion protein $(0,15,50,150,500$, and $1500 \mathrm{ng}$ ) on mouse GDF9 (100 ng) bioactivity, as a luciferase readout from CAGA-luciferase. (C) Effect of the BMPR2ecd-Fc fusion protein $(2 \mu \mathrm{g})$ on BMP2 (100 ng) and BMP6 (100 ng) bioactivity, as a luciferase readout from BRE-luciferase. Data represent the mean \pm s.E.M. of triplicate determination.

mouse GDF9 (Fig. 1B) in $\mathrm{CAGA}_{9}-$ luciferase assay, a reporter for SMAD3 activation. BMPR2ecd-Fc was not able to inhibit activin $A$, activin B, or TGFB1 bioactivity in $\mathrm{CAGA}_{9}$-luciferase assay (data not shown) as shown previously (Gilchrist et al. 2006). We further analyzed BMPR2ecd-Fc bioactivity in BRE-luciferase assay, a reporter for SMAD1/5/8 activation, and found that it was not able to inhibit BMP2 and BMP6 (Fig. 1C). Previously, it has been shown that BMPR2ecd-Fc is not able to inhibit BMP4 (Edwards et al. 2007) and BMP6 (Gilchrist et al. 2006), but is able to inhibit the synergistic effect of GDF9 and BMP15 (Edwards et al. 2007). BMPR2ecd-Fc alone did not induce a signal from either of the reporters.

\section{Study protocol and performance}

In the short-term study, the treatment groups received either $20 \mu \mathrm{g}$ (number of animals per group, $n=6), 60 \mu \mathrm{g}$ $(n=6)$, or $200 \mu \mathrm{g}(n=3)$ of the BMPR2ecd-Fc fusion protein on days $4,6,8,10$, and 12 (Table 1 ). Control mice $(n=5)$ received PBS injections on the given days. An anti-GDF9 MAB \#37 (described previously by Gilchrist et al. (2004)) at a dose of $100 \mu \mathrm{g}(n=3)$ was also tested for its effects on folliculogenesis with an identical injection scheme. However, it did not have a noticeable effect on the development of the follicles (data not shown). In the long-term study (Table 2), the dose of BMPR2ecd-Fc was chosen to be $100 \mu \mathrm{g}$ ( $n=5$ per treatment group) since $60 \mu \mathrm{g}$ that had been used already seemed to be effective in blocking folliculogenesis in the short-term study.

All the animals in the treatment and control groups survived until the end of the studies. No major differences in behavior or body weight were noticed between the groups at the end of the studies. The longterm study was performed once in $\mathrm{FVB} / \mathrm{n}$ strain. The short-term study was repeated three times, twice in the $\mathrm{FVB} / \mathrm{n}$ mouse strain and once in the $\mathrm{C} 57 \mathrm{BI} / \mathrm{N}$ mouse strain $(n=3)$, with identical results.

\section{I.p. injections of the BMPR2ecd-Fc fusion protein inhibit granulosa cell mitogenesis}

GDF9 and BMP15 are known mitogenic oocyte-derived growth factors. In order to study if BMPR2ecd-Fc was able to inhibit granulosa cell mitogenesis in vivo, we first determined the percentage of proliferating cell nuclear antigen (PCNA)-positive cells relative to the total number of the granulosa cells (Fig. 2A, left panel). Additionally, since most of the follicles of the BMPR2ecd-Fc-treated animals are at the primary stage, whereas all early follicle types are well represented in control animals, we also calculated whether there is a difference in the mitogenesis of the granulosa cells residing in proximity to the oocyte, where the concentration of oocyte-derived growth factors is the highest. This analysis confirms that mitogenesis differences are not dependent on the number of granulosa cells within a follicle (Fig. 2A, right panel). In both analyses, the percentage of positively stained cells had decreased $\sim 25 \%$ in the BMPR2ecd-Fc treatment group. Representative sections are shown in Fig. 2B. 
Table 1 Study protocol for the short-term study.

Study protocol (days 0-15)

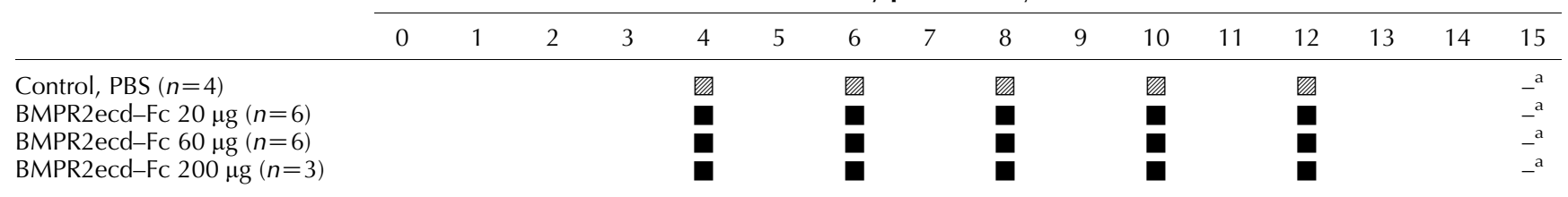

Box with oblique lines, PBS injection; black box, BMPR2ecd-Fc fusion protein injection. $n$, number of animals in the final analysis.

${ }^{\text {a}}$ The animals were killed on day 15 after birth.

\section{I.p. injections of the BMPR2ecd-Fc fusion protein inhibit early folliculogenesis in mice in a dose-dependent manner}

Histological analysis of the ovaries from the short-term study showed that ovarian morphology of the BMPR2ecd-Fc-treated mice is clearly different from that of the control group (Fig. 3). Ovaries of control mice are characterized especially by the presence of types $3 \mathrm{~b}, 4$, and $5 \mathrm{a}$ follicles in roughly equal portions. In contrast, the ovaries of the BMPR2ecd-Fc-treated mice mainly comprise type $3 \mathrm{~b}$ follicles (Fig. $3 \mathrm{C}$ and D).

Follicles in mice treated with a high dose $(200 \mu \mathrm{g} / \mathrm{in}$ jection) of the BMPR2ecd-Fc fusion protein present with atypical characteristics since more than $10 \%$ of these follicles are structurally abnormal. Most abnormal follicles in the treatment groups were located in the cortical layer of the ovary, whereas in the control animals, these follicles were confined to the hilar region of the ovary. We identified abnormally large oocytes $(\geq 20 \mu \mathrm{m})$ surrounded by only one or two granulosa cell layers, and the theca cell layer of these follicles was poorly developed (Fig. 4A and B, black arrows). Furthermore, we observed that the follicles characterized by the presence of a growing oocyte surrounded by one layer of granulosa cells also included flattened and cuboidal granulosa cells (Fig. 4A and B, black arrows). Figure 4C (white arrow) shows an abnormally large oocyte in a type $3 \mathrm{~b}$ follicle.

\section{The BMPR2ecd-Fc fusion protein blocks the paracrine oocyte-granulosa cell communication dose dependently}

The distribution of the follicle types in the BMPR2ecdFc-treated mice is different from that of those in the control group. Figure $5 \mathrm{~A}$ shows that the proportion of primary follicles is increased dose dependently, whereas the proportion of the secondary and tertiary stage follicles (types 4, 5a, and 5b) is clearly decreased dose dependently in the treatment groups. Furthermore, very few type $5 \mathrm{a}$ or $5 \mathrm{~b}$ follicles can be detected in the mice treated with a high dose of BMPR2ecd-Fc (60 or $200 \mu \mathrm{g})$, demonstrating that BMPR2ecd-Fc dose dependently blocks ovarian folliculogenesis beyond the type 4 follicular stage. This suggests that mitogenesis of the granulosa cells is disrupted by introducing BMPR2ecd-Fc i.p. in vivo. The statistical differences are presented in Table 3.

\section{The BMPR2ecd-FC fusion protein promotes the growth} of the oocyte dose dependently in early folliculogenesis

During the follicle growth, the average diameter of the oocyte in each follicle type increases dose dependently for the BMPR2ecd-Fc-treated mice than for the untreated mice (Fig. 5B). The data represent the mean of the oocyte diameter from all the growing oocytes (i.e. follicles with the oocyte diameter $>20 \mu \mathrm{m}$ ) from each treatment group. The oocyte size difference when comparing PBS-treated versus BMPR2ecd-Fc-treated mice is most noticeable within the type $3 b$ follicles, and the statistical significance of the data between different treatment groups is presented in Table 4 . The data reveal that there is very little individual variation within treatment groups; BMPR2ecd-Fc consistently blocks the process of folliculogenesis in vivo.

\section{Electron microscopic analysis of the primary follicles from the short-term study}

In the primary follicular phase, transmission electron microscopic analysis of the ultrastructure of the follicular wall reveals that control and BMPR2ecd-Fctreated mice are phenotypically similar (Fig. 6A and B).

Table 2 Study protocol for the long-term study.

\begin{tabular}{|c|c|c|c|c|c|c|c|c|c|c|c|c|c|c|}
\hline \multirow[b]{2}{*}{ Injection days } & \multicolumn{14}{|c|}{ Study protocol (days 0-32) } \\
\hline & 0 & 4 & 6 & 8 & 11 & 13 & 15 & 18 & 20 & 22 & 25 & 27 & 29 & 32 \\
\hline $\begin{array}{l}\text { Control, PBS }(n=5) \\
\text { BMPR2ecd-Fc } 100 \mu \mathrm{g}(n=5)\end{array}$ & & 勿 & 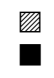 & 狊 & 勿 & 勿 & 勿 & 圆 & 圆 & 第 & 㬟 & 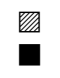 & 罚 & $\begin{array}{l}-^{\mathrm{a}} \\
-^{\mathrm{a}}\end{array}$ \\
\hline
\end{tabular}

Box with oblique lines, PBS injection; black box, BMPR2ecd-Fc-fusion protein injection. $n$, number of animals in the final analysis.

${ }^{a}$ The animals were killed on day 32 after birth. 
A

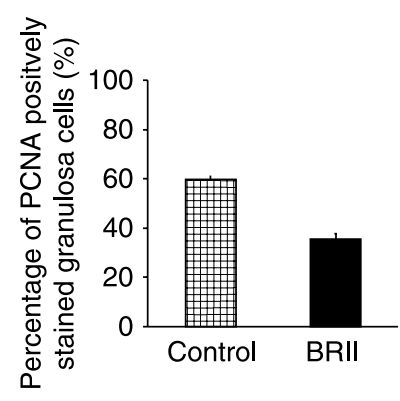

B

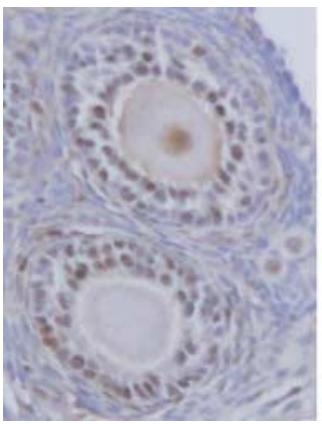

Control
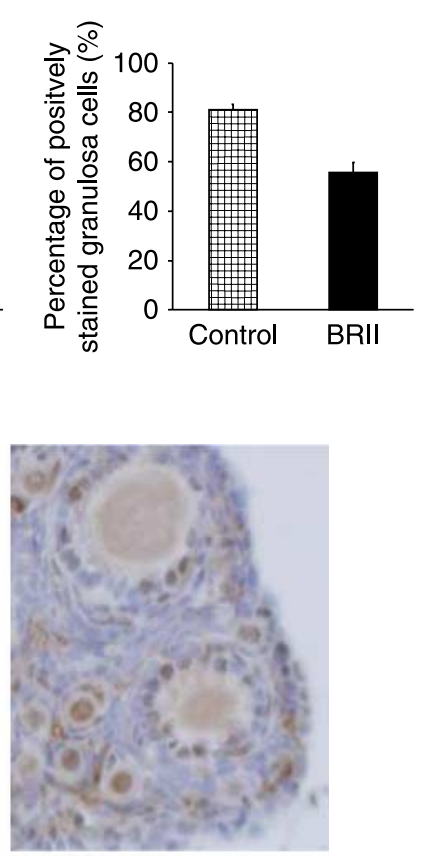

BMPR2-Fc
Figure 2 Mitogenetic analysis of the different treatment groups. (A) (left panel) Percentage of PCNA positively stained granulosa cells out of all the granulosa cells, and (right panel) percentage of positively stained granulosa cells out of the total number of granulosa cells in the first follicle layer. (B) Representative images of follicles from control and BMPR2ecd-Fc-treated animals. Data represent the mean \pm s.E.M. of quadruplicate determination.

The zona pellucida shows transzonal projections in both control and BMPR2ecd-Fc-treated animals. The theca and follicular cells in control and BMPR2ecd-Fc-treated animals contain the basic organelles for protein and steroid synthesis. The lipid droplets in the control group's follicular cells stained generally light gray, whereas those in the BMPR2ecd-Fc-treated cells were mainly darker.

\section{The BMPR2ecd-Fc fusion protein inhibits granulosa cell mitogenesis but allows folliculogenesis to progress during the long-term study}

In a long-term treatment, BMPR2ecd-Fc inhibits the transition between the primary and secondary stages (Fig. 7A). As observed in the short-term study also, oocyte diameter for each follicle type is larger prior to reaching the antral stage. However, once the type $5 b$ stage is reached, the oocyte size remains similar in further follicular stages between the groups (Fig. 7B). The BMPR2ecd-Fc fusion protein inhibits granulosa cell mitogenesis, but nevertheless at this dose it allows folliculogenesis to progress into further developmental stages. In fact, the number of the later stage follicles is increased when compared to the control group (Fig. 7C).

The histological appearance of the BMPR2ecd-Fctreated ovaries revealed that the organ seemed to be functioning normally as demonstrated by the presence of different follicle types ranging from primary stage to corpora lutea (Fig. 7D). In order to study whether the treated ovaries would have smaller antral follicles resulting from a premature antral opening, we measured the size of the antral follicles as the area seen from the equatorial section of the oocyte. However, we did not observe differences between the BMPR2ecd-Fc and control groups (data not shown). We also evaluated the FSH and LH levels in the mice after the long-term treatment in order to rule out systemic effects. The data indicated that there was no statistical difference between the groups (data not shown).
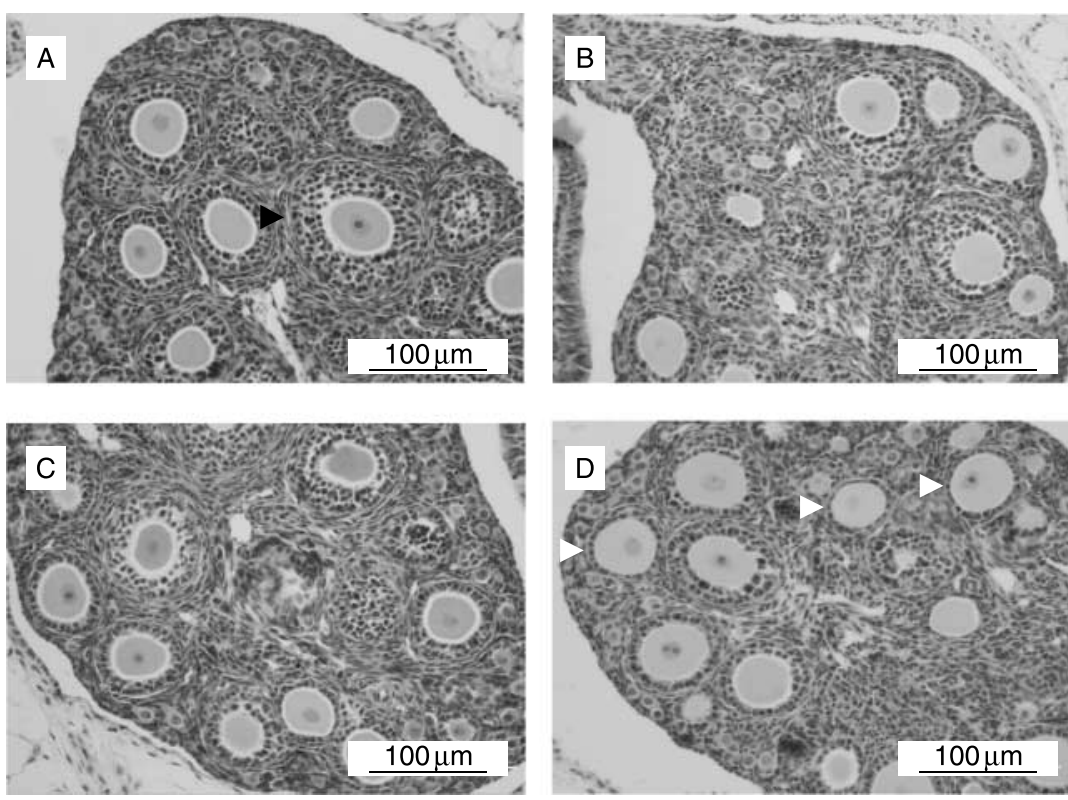

Figure 3 Follicle development in different treatment groups of 15-day-old mice. Histological appearance of 15-day-old mouse ovary given PBS (control, A) or the BMPR2ecd-Fc fusion protein with increasing protein doses (20 $\mu \mathrm{g} \mathrm{B;} 60 \mu \mathrm{g} \mathrm{C}$; and $200 \mu \mathrm{g}$ D). Injection regime described in Table 1. (A) A type $5 \mathrm{a}$ follicle in the control mouse ovary shows well-developed theca layer (black arrow). (C and D) Mostly type $3 \mathrm{~b}$ follicles with large oocytes (white arrow). Magnification $100 \times$. 

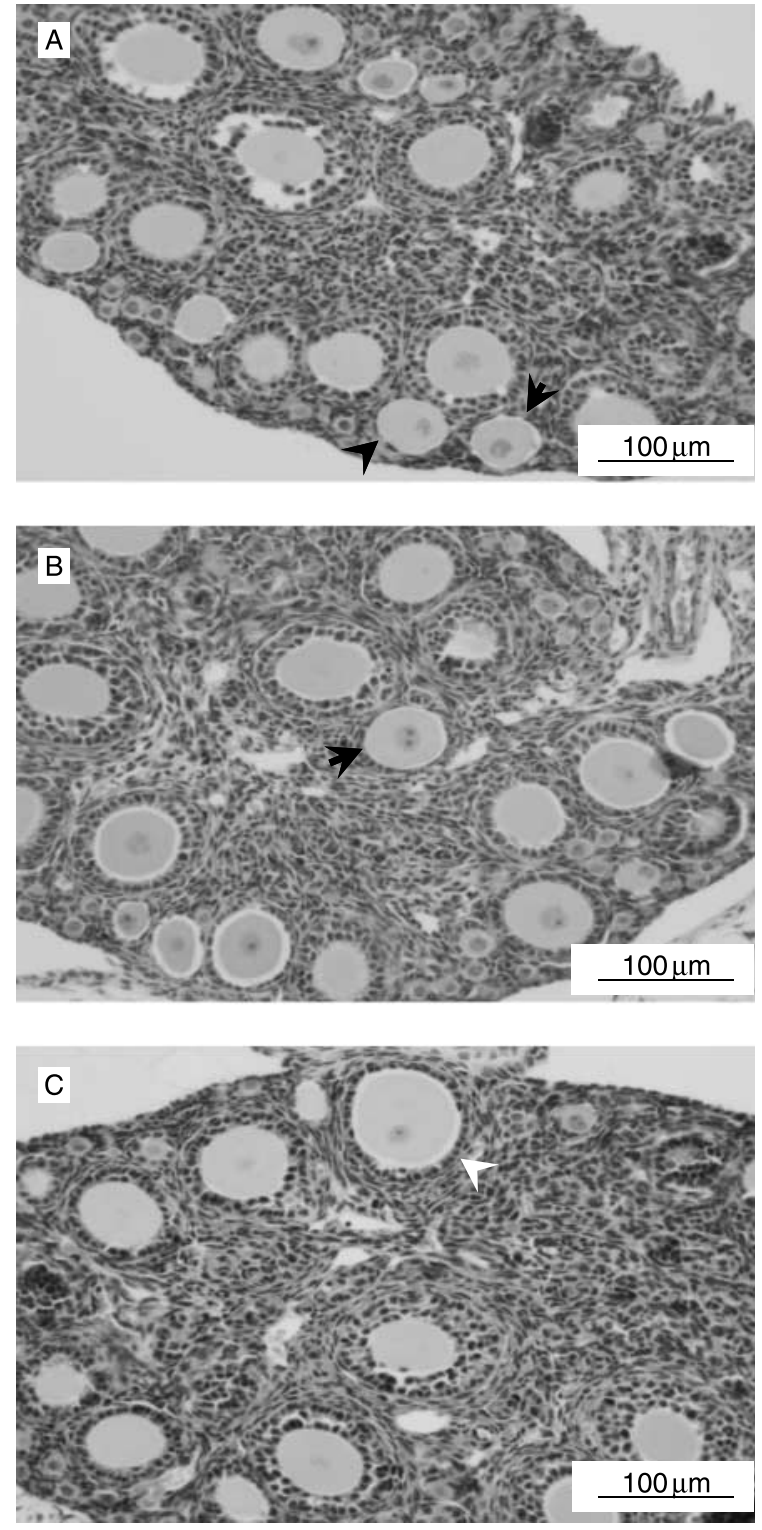

Figure 4 Abnormal follicular architecture in mice treated with $200 \mu \mathrm{g}$ of the BMPR2ecd-Fc fusion protein. (A and B) Relatively large oocytes are surrounded by one layer of cuboidal and flattened granulosa cells (black arrow heads). (C) A highly abnormal type $3 \mathrm{~b}$ follicle (white arrow head) with an oocyte diameter of $66 \mu \mathrm{m}$. Magnification $100 \times$.

\section{Discussion}

In the present study, we investigated for the first time the effect of an established in vitro inhibitor of the oocytederived growth factors (GDF9 and BMP15), namely the BMPR2ecd-Fc fusion protein, on mouse folliculogenesis in vivo. For these purposes, we produced and purified bioactive BMPR2ecd-Fc fusion protein in substantial quantities. We then verified the functionality of BMPR2ecd-FC against several TGFB superfamily members in in vitro assays. We have shown here that the produced BMPR2ecd-Fc is bioactive and is able to inhibit GDF9. We and others have shown previously that
BMPR2ecd-Fc inhibits the cooperative effect of GDF9 and BMP15 (Edwards et al. 2007), and that it also inhibits the mitogenic effects of the oocyte on granulosa and cumulus cells (Gilchrist et al. 2006). Very recently, we were able to inhibit purified human BMP15 with this molecule (MM Pulkki, S Myllymaa, A Pasternack, S Lun, H Ludlow, A Al-Qahtanic, O Korchynskyid, NP Groome, JL Juengel, N Kalkkinen, MPE Laitinen, O Ritvos \& DG Mottershead, unpublished observations). Multiple studies have been conducted to study the functionality of BMPR2ecd-Fc against BMPs and other TGFB superfamily members, but so far, GDF9 and BMP15 remain the only factors that it has been shown to have an effect on. Altogether, these results suggest that the effects of BMPR2ecd-Fc in vivo on ovaries are mainly due to the inhibition of GDF9 and BMP15. With this tool, we addressed two issues: in the initial short-term study, we
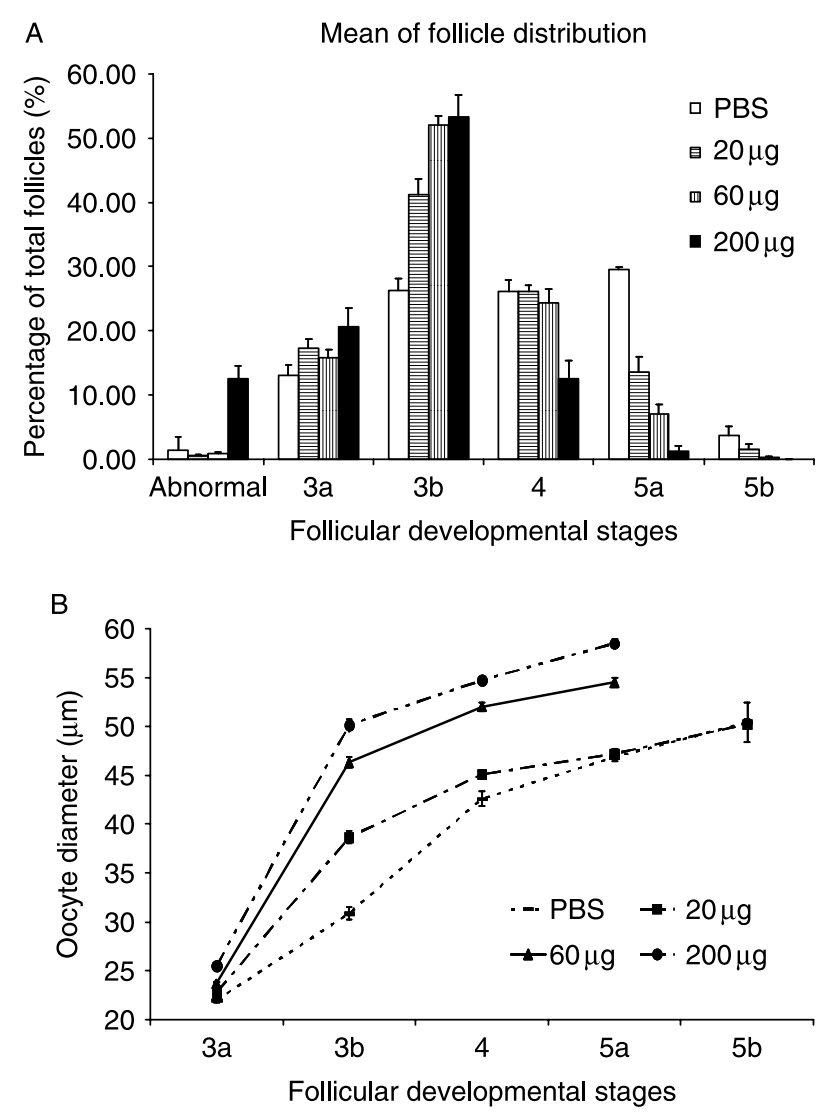

Figure 5 Effect of the BMPR2ecd-Fc fusion protein on mouse folliculogenesis. (A) Distribution of follicles between different developmental stages in mice which received PBS, or 20, 60, or $200 \mu \mathrm{g}$ of the BMPR2ecd-Fc fusion protein. Only those type 3a follicles with a growing oocyte $(\geq 20 \mu \mathrm{m})$ were analyzed. Statistical relevancies are presented in Table 3. (B) Oocyte diameter relative to the follicular stage in control or the BMPR2ecd-Fc fusion protein-treated mice. Ovaries were serially sectioned, and every section was taken into the analysis. The statistical significances between the different treatment groups are presented in Table 4. Only two type $5 \mathrm{~b}$ follicles were found in the $60-\mu \mathrm{g}$ treatment group out of the total of 959 follicles. Data represent the mean \pm S.E.M. per animal. 
Table 3 Statistical analysis of the data presented in Fig. 5A.

\begin{tabular}{|c|c|c|c|c|c|c|}
\hline & \multicolumn{6}{|c|}{ Follicle type } \\
\hline & Abnormal & 3а & $3 b$ & 4 & $5 a$ & $5 b$ \\
\hline Control versus $20 \mu \mathrm{g}$ & NS & NS & $\leq 0.05$ & NS & $\leq 0.01$ & NS \\
\hline Control versus $60 \mu \mathrm{g}$ & NS & NS & $\leq 0.01$ & NS & $\leq 0.001$ & NS \\
\hline Control versus $200 \mu \mathrm{g}$ & $\leq 0.05$ & NS & $\leq 0.01$ & $\leq 0.05$ & $\leq 0.001$ & - \\
\hline 20 vs $60 \mu \mathrm{g}$ & $\bar{N} S$ & NS & $\leq 0.05$ & $\bar{N} S$ & $\bar{N} S$ & NS \\
\hline 20 vs $200 \mu \mathrm{g}$ & $\leq 0.01$ & NS & NS & $\leq 0.05$ & $\leq 0.05$ & - \\
\hline 60 vs $200 \mu \mathrm{g}$ & $\leq 0.05$ & NS & NS & $\leq 0.05$ & $\leq 0.05$ & - \\
\hline
\end{tabular}

$P$ values $\leq$, NS, not significant.

wanted to determine if this recombinant BMPR2ecd-Fc fusion protein would affect the development of preantral follicles, and in the long-term study, we tested whether it is possible to disrupt the whole process of folliculogenesis.

Evidently, we were able to modulate ovarian folliculogenesis by the BMPR2ecd-Fc fusion protein in juvenile mice in vivo. The treatment caused a block in early folliculogenesis by inhibiting granulosa cell mitogenesis, mimicking to some extent the phenotype observed in the GDF9 knockout mice in which proliferation of granulosa cells was halted at the primary stage (Carabatsos et al. 1998, Elvin et al. 1999). The effects observed are also in line with the proposed actions of GDF9 on bovine granulosa and theca cells (Spicer et al. 2008). In the same study, it was also established that theca cells were responsive to GDF9. A MAB for GDF9, \#37 (Gilchrist et al. 2004), was not able to affect folliculogenesis, and this might be due to a lower binding capacity or to the inability of the antibody to access ligand within the ovary.

By administering BMPR2ecd-Fc into mice, we demonstrated a blockage in the transition between primary (type 3b) to secondary (type 4) follicles and also in the transition from secondary (type 4) to tertiary (type 5a) follicles. The fact that we were able to cause this effect in a dose-dependent manner demonstrates that the phenomenon can be controlled with an appropriate administration of the BMPR2ecd-Fc fusion protein. The inhibition in the transition from primary to secondary follicles is the inverse phenomenon to that which was found in a recent study where a modified form of mouse BMP15 was overexpressed, resulting in the transition from primary to secondary follicles being accelerated (McMahon et al. 2008).
In our studies, a dramatic increase in oocyte size per follicle type was noticed. This was most notable in the type $3 \mathrm{~b}$ follicles in mice treated with $200 \mu \mathrm{g}$ of BMPR2ecd-Fc. A similar phenomenon has been observed previously in GDF9-deficient mice (Carabatsos et al. 1998). This might be due to the upregulation of $\mathrm{KL}$ as suggested by studies in vitro and GDF9-deficient mice (Packer et al. 1994, Elvin et al. 1999). The increase in oocyte size and the effect on folliculogenesis appear to be dependent on the dose of BMPR2ecd-Fc administered. The highest dose resulted in more abnormal follicles being found. These follicles had a mixture of squamous and cuboidal granulosa cells, and the oocyte size was already as large as in the antral follicles.

The ultrastructural similarity between the primary follicles from the control and BMPR2ecd-Fc-treated mice suggests that the effects of the modulation of the folliculogenesis are primarily at the level of cell growth and differentiation, which is also supported by the persistence of ovulatory function in the long-term study. The presence of transzonal projections indicates that in BMPR2ecd-Fc-treated mice also, the oocyte is able to form physical contacts with cumulus granulosa cells. Hence, nutrient and small molecule trafficking between the oocyte and the cytoplasm of the surrounding granulosa cells may well not be altered by our BMPR2ecd-Fc treatment. The darker stained lipid droplets generally found in the follicular cells of the BMPR2ecd-Fc-treated mice suggest that they may contain steroids or phospholipids, which generally bind more osmium, and thus, stain darker than triglycerides and simple fats. This may suggest differences

Table 4 Statistical significance of the data presented in Fig. 5B.

\begin{tabular}{|c|c|c|c|c|c|}
\hline & \multicolumn{5}{|c|}{ Follicle type } \\
\hline & $3 a$ & $3 b$ & 4 & $5 a$ & $5 b$ \\
\hline Control versus $20 \mu \mathrm{g}$ & NS & $\leq 0.001$ & $\leq 0.01$ & NS & NS \\
\hline Control versus $60 \mu \mathrm{g}$ & $\leq 0.01$ & $\leq 0.001$ & $\leq 0.001$ & $\leq 0.001$ & NS \\
\hline Control versus $200 \mu \mathrm{g}$ & $\leq 0.01$ & $\leq 0.001$ & $\leq 0.001$ & $\leq 0.01$ & - \\
\hline 20 vs $60 \mu \mathrm{g}$ & NS & $\leq 0.001$ & $\leq 0.001$ & $\leq 0.001$ & NS \\
\hline 20 vs $200 \mu \mathrm{g}$ & $\leq 0.05$ & $\leq 0.001$ & $\leq 0.001$ & $\leq 0.01$ & - \\
\hline 60 vs $200 \mu \mathrm{g}$ & NS & $\leq 0.01$ & $\leq 0.01$ & $\leq 0.05$ & - \\
\hline
\end{tabular}

$P$ values $\leq$, NS, not significant. 

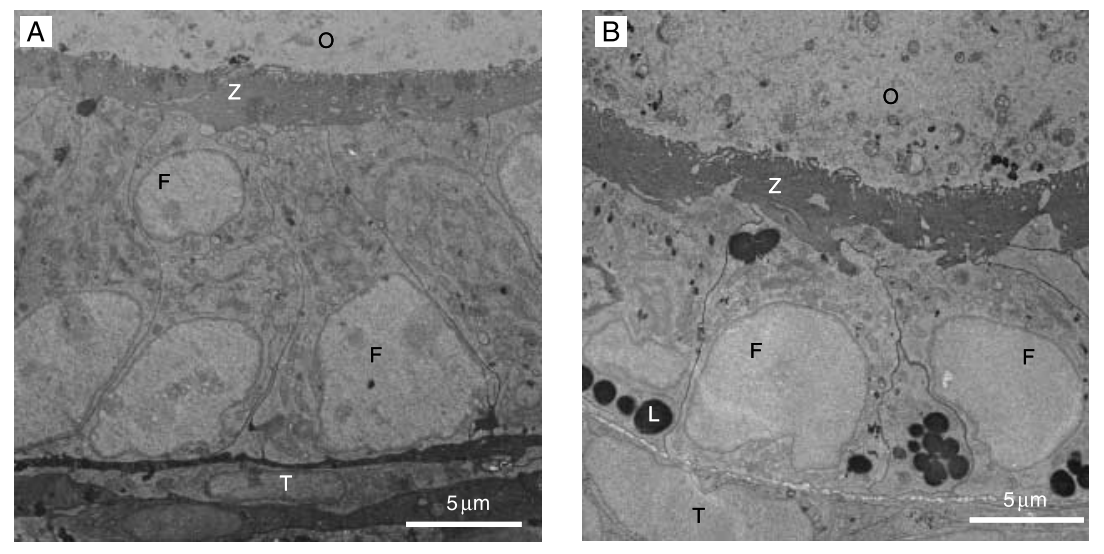

Figure 6 Transmission electron micrograph of the follicular wall of primary ovarian follicles. (A) A representative section from a control mouse and (B) a section from a BMPR2ecd-Fc proteintreated mouse. The granulosa cells (F) form one to two layers of low columnar cells. Their processes protrude into the zona pellucida $(Z)$, where similar processes of the oocyte $(\mathrm{O})$ protrude toward the follicular cells. The cytoplasm is rich in mitochondria and other organelles of the protein and steroid secretory pathway and lipid droplets (L). The theca cells $(\mathrm{T})$ are elongated spindleshaped cells with respective organelles. in cholesterol biosynthesis in the follicular cells between the control and BMPR2ecd-Fc-treated mice.

With the longer study protocol, we wanted to determine the effects of the BMPR2ecd-Fc fusion protein on larger follicles and ovulation, and whether we can block the whole process of folliculogenesis. However, we were not able to block folliculogenesis completely with the dosage used, as larger follicles, i.e. antral and preovulatory follicles, as well as corpora lutea were also present in the BMPR2ecd-Fc-treated mice. The dose of $100 \mu \mathrm{g}$ was not probably enough to shut down folliculogenesis. On the contrary, we were able to observe more antral follicles and corpora lutea in the BMPR2ecd-Fc-treated mice. We hypothesize that the treatment leads to the inhibition of the suppressive effects of GDF9 and BMP15 on gonadotropin sensitivity, especially in the later stages of the folliculogenesis (Erickson \& Shimasaki 2001, Spicer et al. 2008). However, when treated with BMPR2ecd-Fc, we were able to detect effects on transitions between the follicle types $3 \mathrm{~b}-5 \mathrm{a}$ in the long-term study which were similar to those seen in the short-term study. Also, the mean of oocyte diameter per follicular stage was increased in a similar fashion, but already the 5b type follicles' oocyte diameters were equal, demonstrating that oocyte does not grow larger when treated with BMPR2ecd-Fc. We also measured serum gonadotropins $\mathrm{FSH}$ and $\mathrm{LH}$ but found no differences in these hormone levels, suggesting that the observed phenomena were not caused by systemic effects but are primarily due to the inhibition of paracrine signaling and derivatives of that. This inability to disrupt folliculogenesis with the use of BMPR2ecd-Fc might be due to the dosage that was too small, or that simply in older, more mature mice, androgens and extraovarian hormonal stimuli replace partially paracrine signaling.

Taken together, our studies suggest that it is possible to control ovarian paracrine signaling with the BMPR2ecd-Fc fusion protein, causing a phenotype partially resembling that of oocyte-derived factor-deficient
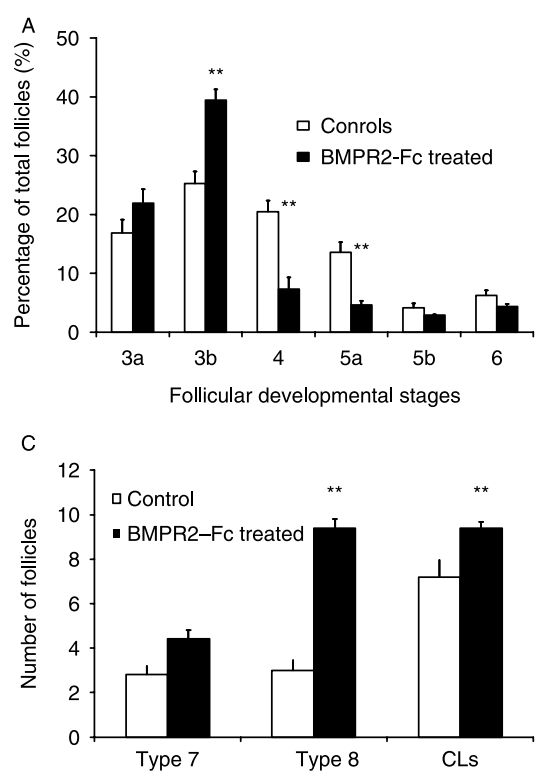

B

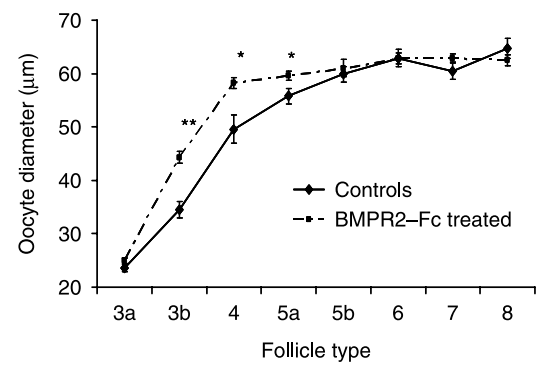

D

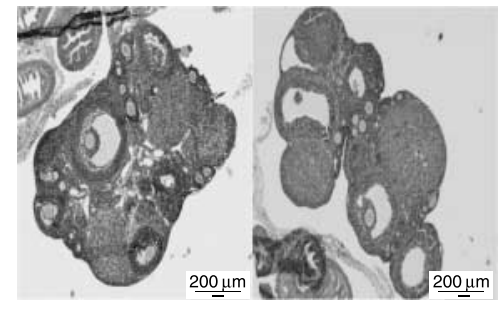

Figure 7 Analysis of the long-term treatment with the BMPR2ecd-Fc fusion protein. (A) Distribution of the different follicular developmental stages in control and BMPR2ecd-Fc-treated mice. (B) The mean of the oocyte diameter is displayed per follicle type. (C) Mean distribution of larger follicles is represented. Data represent the mean \pm S.E.M. per animal. Note that statistical significance is represented as S.D. for $C(* P \leq 0.05$; $\left.{ }^{* *} P \leq 0.01\right)$. CLs, corpora lutea. (D) A representative section of histological appearance of the ovaries of 32-day-old mice receiving either PBS (left panel) or $100 \mu \mathrm{g}$ of the BMPR2ecd-Fc fusion protein (right panel). The injection regime was as described in Table 2. All developmental stages of folliculogenesis are found in both groups. Magnification $50 \times$. 
knockout mouse lines. By administering BMPR2ecd-Fc, we were able to 1 ) inhibit granulosa cell mitogenesis, 2) cause a block in folliculogenesis between primary and secondary follicles, 3) cause a dramatic increase in the oocyte size at the primary follicular stage, and 4) cause an increase in the number of antral follicles and corpora lutea. Since the use of the BMPR2ecd-Fc fusion protein enables the modulation of ovarian folliculogenesis dose dependently, the examination of the detailed effects of the oocyte-derived growth factors during different ovarian functions is feasible.

\section{Materials and Methods \\ BMPR2-Fc fusion protein}

\section{Production of BMPR2ecd-Fc-expressing $\mathrm{CHO}$ cells}

The human BMPR2 ectodomain was amplified via PCR with the following primers: GCGCTAGCATGACTTCCTCGCTGCAG and GCGGATCCGCCTCATCTCGGTTAAATGAATGAGG from a plasmid containing the human BMPR2 sequence and cloned into the plgPlus vector (R\&D Systems, Minneapolis, $M N$, USA). A version of the human IgG1 Fc domain incorporating a C-terminal His6 tag was produced by PCR amplifying the Fc domain (GCAGATCTAATCGAAGGTCGTGGTGATCCCAAATCTTGTGAC and AAGCGGCCGCTCAATGGTGATGGTGATGGTGTTTACCCGGAGACAGGGA) from the plgPlus expression plasmid. The PCR products were subcloned into the pGEM-T easy (Promega) vectors, sequenced, and fused before cloning into the expression vector pEFIRES-p (Hobbs et al. 1998).

Chinese hamster ovary $(\mathrm{CHO})$ cells transfected with the BMPR2ecd-Fc expression vector were selected with puromycin (Sigma-Aldrich) as described (Kaivo-Oja et al. 2003). During expansion, cells were grown in IMDM supplemented with $10 \%$ FCS. DMEM-Hams F-12 (1:1) supplemented with 0.5\% FCS was used as the production medium. $\mathrm{CHO}$ cells were stably producing BMPR2ecd-Fc, 5-10 mg/l of culture media.

\section{Purification of BMPR2ecd-FC}

Cell culture supernatants were clarified by filtration through 0.45- $\mu \mathrm{m}$ membrane (Steritop, Millipore, Billerica, MA, USA). $\mathrm{NaCl}, 1 \mathrm{M}$, and imidazole, $5 \mathrm{mM}$, were added into the clarified supernatants, and the solution was pumped through a $\mathrm{Ni}^{2+}$ loaded HiTrap column (GE Healthcare Life Sciences, Uppsala, Sweden) at $4{ }^{\circ} \mathrm{C}$. The same protocol was used for all the purifications: washes with $10(50 \mathrm{ml}), 20(50 \mathrm{ml})$, and $50 \mathrm{mM}$ imidazole $(25 \mathrm{ml})$, and elutions $(5 \mathrm{ml})$ with $2 \times 100$ and $4 \times 250 \mathrm{mM}$ imidazole. All buffers also contained $0.2 \mathrm{M} \mathrm{NaCl}$ and $0.02 \mathrm{M} \mathrm{NaHPO}_{4}, \mathrm{pH}$ 7.2. The column was stripped with EDTA between purifications and was re-loaded with $\mathrm{Ni}^{2+}$.

\section{Western blotting and silver staining}

All the purification steps were analyzed on silver gels and western blots. Samples were reduced with $10 \mathrm{mM}$ dithiothreitol and run on $10 \%$ SDS-PAGE gels, stained with silver nitrate or blotted onto a Hybond $\mathrm{C}$ nitrocellulose membrane as described previously (Kaivo-Oja et al. 2003). Blotted membranes were treated with anti-His primary antibody (1:10 000; GE Healthcare Life Sciences) and a secondary antibody, peroxidase-conjugated anti-lgG (1:20 000; Jackson ImmunoResearch Laboratories, Suffolk, UK) or alkaline phosphatase-conjugated anti-IgG (Bio-Rad). Immunoreactive proteins were detected using ECL reagents (GE Healthcare Life Sciences) or by alkaline phosphatase-based detection (Bio-Rad). Dimerization and secondary antibody control were done to secure that there was no FCS carry-over in our sample, and there was no signal detected (data not shown). Also, it was confirmed by HPLC followed by mass spectrometry analysis that the purified protein was the BMPR2ecd-Fc fusion protein (data not shown).

\section{Dialysis, concentration, and quantitation of protein}

The peak fractions were pooled and dialyzed against sterile PBS at $4{ }^{\circ} \mathrm{C}$ to dilute the imidazole concentration in the sample down to the picomolar range. Amicon Ultra-15 concentrators (Millipore) were used to concentrate the sample 20-fold, and the BMPR2ecd-Fc fusion protein remained soluble. u.v. and BCA assays (Thermo Fischer Scientific, Rockford, IL, USA) were used to determine the protein concentration. The sample was stored in $1.5-\mathrm{ml}$ low-protein binding tubes (Eppendorf, Hamburg, Germany) at $-70^{\circ} \mathrm{C}$.

\section{BMPR2ecd-Fc treatments in mice}

All animal experimentation was conducted in accordance with the institutional animal care policies of the University of Turku (Turku, Finland). Animal experiments were approved by the respective authorities, and the institutional policies on animal experimentation fully met the requirements as defined in the $\mathrm{NIH}$ Guide on animal experimentation. The animals were housed under controlled environmental conditions $(12 \mathrm{~h}$ light: $12 \mathrm{~h}$ darkness, temperature $21 \pm 1^{\circ} \mathrm{C}$ ) at the Animal Facility of University of Turku. Soy-free SDS RM3 (Special Diet Service; Whitman, Essex, UK) and tap water were available ad libitum. Newborn female mice were chosen randomly to study groups. Mice were injected i.p. with $20 \mu \mathrm{l}$ of either the BMPR2ecd-Fc fusion protein or PBS starting at postnatal day 4 (injection regime presented in Table 1). Special care was taken to avoid perforating abdominal organs.

\section{Histological procedures: follicle counting}

After removal, tissues were fixed in $4 \%$ paraformaldehyde (PFA) and embedded in paraffin. Ovaries were serially sectioned throughout, and $5-\mu \mathrm{m}$ sections were stained by standard hematoxylin-eosin staining for histological analysis. All the sections were photographed under light microscopy. In total, 3000 follicles from 19 animals from the short-term study and 1900 follicles from 10 animals from the long-term study were subjected to the analysis. Special care was taken that each follicle was counted only once, and the section in which the nucleolus of the oocyte of each follicle was the most prominent was the section on which the analyses were done. All the analyses were carried out in a blind manner. 
The classification of the oocytes and follicles was performed according to Pedersen \& Peters (1968), a scheme based on 1 ) the size of the oocyte, 2) the size of the follicle as defined by the number of granulosa cells, and 3) the morphology of the follicle. In brief, the follicles were divided into:

Type 3a: Small oocyte surrounded by a single ring of cuboidal granulosa cells, not more than 20 granulosa cells on the largest cross section.

Type 3b: Growing oocyte surrounded by a ring of 21-60 granulosa cells.

Type 4: Growing oocyte surrounded by two layers of granulosa cells (61-100).

Type 5a: The oocyte is enveloped in three layers of granulosa cells (101-200).

Type 5b: A large oocyte surrounded by many layers of granulosa cells (201-400).

Type 6: A large oocyte with 400-600 granulosa cells.

Type 7: An antral follicle with a single cavity of follicle fluid. The cumulus oophorus but not its stalk has formed.

Type 8: Preovulatory follicle with a single cavity of fluid and a well-formed cumulus stalk.

\section{Atretic/abnormal}

Follicles which meet two of the following three criteria are to be classified under the category abnormal:

1) Oocyte is malformed or partial.

2) Granulosa cells are flattened or mixture of flattened and cuboidal or severely disorganized.

3) Oocyte has disappeared and its remnants and granulosa cells are left.

In the analysis of type 3a follicles, only those follicles with a growing oocyte $(\geq 20 \mu \mathrm{m})$ were counted. The numbers of primordial ovarian follicles classified into type 1 or type 2 were not analyzed.

\section{Statistics: follicle counting}

Statistics for follicle counting in Figs $5 \mathrm{~A}$ and $\mathrm{B}$ and $7 \mathrm{~A}$ and $\mathrm{B}$ were calculated from the means per animal, and one-way ANOVA was performed from these. In Fig. 7C, since the number of the larger follicles is relatively low, we decided to employ s.D. Relative $P$ values were calculated from these for each treatment group.

\section{Mitogenesis analysis of granulosa cells}

Paraffin-embedded ovaries from four mice per group were sectioned into 5 - $\mu \mathrm{m}$ sections, and four sections per glass slide were prepared. PCNA staining was performed with mouse anti-PCNA MAB (1:200 dilution; Chemicon international, Temecula, CA, USA) and counterstaining was done with standard hematoxylin-eosin. Four mice from the control group (in total 60 follicles) and four mice from the BMPR2-treated $(60 \mu \mathrm{g})$ group (65 follicles) from the short-term study were randomly selected for granulosa cell mitogenesis analysis. Data are the mean \pm s.E.M. of quadruplicate determinations.

\section{In vitro bioassays}

Bioassays to test the bioactivity and specificity of BMPR2ecdFc were done in established signaling assays. In short, human granulosa luteal, COV434, or HepG2 cells were introduced with either $\mathrm{CAGA}_{9}$-luciferase or BRE-luciferase reporter, after which the desired ligands were introduced into the cells, and the following day, luciferase readout was measured as described previously (Kaivo-Oja et al. 2005, Mottershead et al. 2008). Data are the mean \pm s.E.M. of triplicate determinations from representative experiments, relative to an adjusted value of 1.0 for the mean of the control wells (Kaivo-Oja et al. 2003). These two reporter assays were repeated three to four times with corresponding results.

\section{Electron microscopy}

The removed ovaries were fixed with freshly prepared $5 \%$ glutaraldehyde (Electron Microscopy Sciences, Fort Washington, PA, USA). The specimens were prepared according to standard procedures as described previously (Fröjdman et al. 1992). Orientation sections for light microscopy were cut at $1-\mu \mathrm{m}$ thickness and were stained with toluidine blue. The thin sections $(70 \mathrm{~nm})$ were stained with $5 \%$ uranyl acetate and $5 \%$ lead citrate in Ultrostainer (Leica, Wien, Austria) and were examined with a JEM 1200EX (JEOL, Tokyo, Japan) transmission electron microscope.

\section{Declaration of interest}

The authors declare that there is no conflict of interest that could be perceived as prejudicing the impartiality of the research reported.

\section{Funding}

These studies were supported by grants from the Academy of Finland, the Finnish Funding Agency for Technology and Innovation, the Helsinki University research funds, the Juselius Foundation, the Jalmari and Rauha Ahokas Foundation, the Novo Nordisk Foundation, the Orion-Farmos Research Foundation, the Paulo Foundation, and the Jenny and Antti Wihuri Foundation.

\section{Acknowledgements}

We thank the people in the Department of Physiology, Institute of Biomedicine and Laboratory of Electron Microscopy at the University of Turku, for technical assistance. We would also like to thank Marjo Rissanen at the University of Helsinki.

\section{References}

Carabatsos MJ, Elvin J, Matzuk MM \& Albertini DF 1998 Characterization of oocyte and follicle development in growth differentiation factor9-deficient mice. Developmental Biology 204 373-384.

Chamow SM \& Ashkenazi A 1996 Immunoadhesins: principles and applications. Trends in Biotechnology 14 52-60.

Chand AL, Ponnampalam AP, Harris SE, Winship IM \& Shelling AN 2006 Mutational analysis of BMP15 and GDF9 as candidate genes for premature ovarian failure. Fertility and Sterility 86 1009-1012. 
Chen AQ, Yu SD, Wang ZG, Xu ZR \& Yang ZG 2008 Stage-specific expression of bone morphogenetic protein type I and type II receptor genes: effects of follicle-stimulating hormone on ovine antral follicles. Animal Reproduction Science 111 391-399.

Di Pasquale E, Beck-Peccoz P \& Persani L 2004 Hypergonadotropic ovarian failure associated with an inherited mutation of human bone morphogenetic protein-15 (BMP15) gene. American Journal of Human Genetics 75 106-111.

Dragovic RA, Ritter LJ, Schulz SJ, Amato F, Thompson JG, Armstrong DT \& Gilchrist RB 2007 Oocyte-secreted factor activation of SMAD 2/3 signaling enables initiation of mouse cumulus cell expansion. Biology of Reproduction 76 848-857.

Durlinger AL, Gruijters MJ, Kramer P, Karels B, Ingraham HA, Nachtigal MW, Uilenbroek JT, Grootegoed JA \& Themmen AP 2002 Anti-Müllerian hormone inhibits initiation of primordial follicle growth in the mouse ovary. Endocrinology 143 1076-1084.

Edwards SJ, Reader KL, Lun S, Western A, Lawrence S, McNatty KP \& Juengel JL 2007 The cooperative effect of growth and differentiation factor-9 and bone morphogenetic protein (BMP)-15 on granulosa cell function is modulated primarily through BMP receptor II. Endocrinology 149 1026-1030.

Elvin JA, Yan C, Wang P, Nishimori K \& Matzuk MM 1999 Molecular characterization of the follicle defects in the growth differentiation factor 9-deficient ovary. Molecular Endocrinology 13 1018-1034.

Erickson GF \& Shimasaki S 2001 The physiology of folliculogenesis: the role of novel growth factors. Fertility and Sterility 76 943-949.

Fröjdman K, Paranko J, Virtanen I \& Pelliniemi LJ 1992 Intermediate filaments and epithelial differentiation of male rat embryonic gonad. Differentiation 50 113-123.

Galloway SM, McNatty KP, Cambridge LM, Laitinen MP, Juengel JL, Jokiranta TS, McLaren RJ, Luiro K, Dodds KG, Montgomery GW et al. 2000 Mutations in an oocyte-derived growth factor gene (BMP15) cause increased ovulation rate and infertility in a dosage-sensitive manner. Nature Genetics 25 279-283.

Gilchrist RB, Ritter LJ, Cranfield M, Jeffery LA, Amato F, Scott SJ, Myllymaa S, Kaivo-Oja N, Lankinen H, Mottershead DG et al. 2004 Immunoneutralization of growth differentiation factor 9 reveals it partially accounts for mouse oocyte mitogenic activity. Biology of Reproduction 71 732-739.

Gilchrist RB, Ritter LJ, Myllymaa S, Kaivo-Oja N, Dragovic RA, Hickey TE, Ritvos O \& Mottershead DG 2006 Molecular basis of oocyte-paracrine signaling that promotes granulosa cell proliferation. Journal of Cell Science 119 3811-3821.

Hobbs S, Jitrapakdee S \& Wallace JC 1998 Development of a bicistronic vector driven by the human polypeptide chain elongation factor 1alpha promoter for creation of stable mammalian cell lines that express very high levels of recombinant proteins. Biochemical and Biophysical Research Communications 252 368-372.

Hutt KJ \& Albertini DF 2007 An oocentric view of folliculogenesis and embryogenesis. Reproductive Biomedicine Online 14 758-764.

Joyce IM, Clark AT, Pendola FL \& Eppig JJ 2000 Comparison of recombinant growth differentiation factor-9 and oocyte regulation of KIT ligand messenger ribonucleic acid expression in mouse ovarian follicles. Biology of Reproduction 63 1669-1675.

Kaivo-Oja N, Bondestam J, Kämäräinen $M$, Koskimies J, Vitt $U$, Cranfield M, Vuojolainen K, Kallio JP, Olkkonen VM, Hayashi $M$ et al. 2003 Growth differentiation factor-9 induces Smad2 activation and inhibin B production in cultured human granulosa-luteal cells. Journal of Clinical Endocrinology and Metabolism 88 755-762.

Kaivo-Oja N, Mottershead DG, Mazerbourg S, Myllymaa S, Duprat S, Gilchrist RB, Groome NP, Hsueh AJ \& Ritvos O 2005 Adenoviral gene transfer allows Smad-responsive gene promoter analyses and delineation of type I receptor usage of transforming growth factor-beta family ligands in cultured human granulosa luteal cells. Journal of Clinical Endocrinology and Metabolism 90 271-278.

Klinger FG \& De Felici M 2002 In vitro development of growing oocytes from fetal mouse oocytes: stage-specific regulation by stem cell factor and granulosa cells. Developmental Biology 244 85-95.

Knight PG \& Glister C 2006 TGF-beta superfamily members and ovarian follicle development. Reproduction 132 191-206.
Kovanci E, Rohozinski J, Simpson JL, Heard MJ, Bishop CE \& Carson SA 2007 Growth differentiating factor-9 mutations may be associated with premature ovarian failure. Fertility and Sterility 87 143-146.

Laissue P, Christin-Maitre S, Touraine P, Kuttenn F, Ritvos O, Aittomaki K, Bourcigaux N, Jacquesson L, Bouchard P, Frydman R et al. 2006 Mutations and sequence variants in GDF9 and BMP15 in patients with premature ovarian failure. European Journal of Endocrinology 154 739-744.

Laitinen M, Vuojolainen K, Jaatinen R, Ketola I, Aaltonen J, Lehtonen E, Heikinheimo M \& Ritvos O 1998 A novel growth differentiation factor-9 (GDF9) related factor is co-expressed with GDF9 in mouse oocytes during folliculogenesis. Mechanisms of Development 78 135-140.

Mace PD, Cutfield JF \& Cutfield SM 2006 High resolution structures of the bone morphogenetic protein type II receptor in two crystal forms: implications for ligand binding. Biochemical and Biophysical Research Communications 351 831-838.

Mazerbourg S, Klein C, Roh J, Kaivo-Oja N, Mottershead DG, Korchynskyi O, Ritvos O \& Hsueh AJ 2004 Growth differentiation factor-9 signaling is mediated by the type I receptor, activin receptor-like kinase 5. Molecular Endocrinology 18 653-665.

McMahon HE, Hashimoto O, Mellon PL \& Shimasaki S 2008 Oocytespecific over-expression of mouse BMP15 leads to accelerated folliculogenesis and an early onset of acyclicity in transgenic mice. Endocrinology 149 2807-2815.

McNatty KP, Juengel JL, Reader KL, Lun S, Myllymaa S, Lawrence SB, Western A, Meerasahib MF, Mottershead DG, Groome NP et al. 2005a Bone morphogenetic protein 15 and growth differentiation factor 9 co-operate to regulate granulosa cell function. Reproduction $\mathbf{1 2 9}$ 473-480.

McNatty KP, Juengel JL, Reader KL, Lun S, Myllymaa S, Lawrence SB, Western A, Meerasahib MF, Mottershead DG, Groome NP et al. $2005 b$ Bone morphogenetic protein 15 and growth differentiation factor 9 co-operate to regulate granulosa cell function in ruminants. Reproduction 129 481-487.

McNatty KP, Juengel JL, Wilson T, Galloway SM, Davis GH, Hudson NL, Moeller CL, Cranfield M, Reader KL, Laitinen MP et al. 2006 Oocytederived growth factors and ovulation rate in sheep. Reproduction Supplement 61 339-351.

McPherron AC \& Lee SJ 1993 GDF-3 and GDF9: two new members of the transforming growth factor-beta superfamily containing a novel pattern of cysteines. Journal of Biological Chemistry 268 3444-3449.

Montgomery GW, Zhao ZZ, Marsh AJ, Mayne R, Treloar SA, James M, Martin NG, Boomsma DI \& Duffy DL 2004 A deletion mutation in GDF9 in sisters with spontaneous DZ twins. Twin Research 7 548-555.

Moore RK, Otsuka F \& Shimasaki S 2003 Molecular basis of bone morphogenetic protein-15 signaling in granulosa cells. Journal of Biological Chemistry 278 304-310.

Mottershead DG, Pulkki MM, Muggalla P, Pasternack A, Tolonen M, Myllymaa S, Korchynskyi O, Nishi Y, Yanase T, Lun S et al. 2008 Characterization of recombinant human growth differentiation factor-9 signaling in ovarian granulosa cells. Molecular and Cellular Endocrinology 283 58-67.

Nilsson EE \& Skinner MK 2002 Growth and differentiation factor-9 stimulates progression of early primary but not primordial rat ovarian follicle development. Biology of Reproduction 67 1018-1024.

Otsuka F \& Shimasaki S 2002 A negative feedback system between oocyte bone morphogenetic protein 15 and granulosa cell kit ligand: its role in regulating granulosa cell mitosis. PNAS 99 8060-8065.

Packer AI, Hsu YC, Besmer P \& Bachvarova RF 1994 The ligand of the c-kit receptor promotes oocyte growth. Developmental Biology $\mathbf{1 6 1}$ 194-205.

Palmer JS, Zhao ZZ, Hoekstra C, Hayward NK, Webb PM, Whiteman DC, Martin NG, Boomsma DI, Duffy DL \& Montgomery GW 2006 Novel variants in growth differentiation factor 9 in mothers of dizygotic twins. Journal of Clinical Endocrinology and Metabolism 91 4713-4716.

Pedersen T \& Peters H 1968 Proposal for a classification of oocytes and follicles in the mouse ovary. Journal of Reproduction and Fertility $\mathbf{1 7}$ 555-557. 
Reddy P, Liu L, Adhikari D, Jagarlamudi K, Rajareddy S, Shen Y, Du C, Tang W, Hämäläinen T, Peng SL et al. 2008 Oocyte-specific deletion of Pten causes premature activation of the primordial follicle pool. Science 319 611-613.

Roh JS, Bondestam J, Mazerbourg S, Kaivo-Oja N, Groome N, Ritvos O \& Hsueh AJ 2003 Growth differentiation factor-9 stimulates inhibin production and activates Smad2 in cultured rat granulosa cells. Endocrinology 144 172-178.

Spicer LJ, Aad PY, Allen DT, Mazerbourg S, Payne AH \& Hsueh AJ 2008 Growth differentiation factor 9 (GDF9) stimulates proliferation and inhibits steroidogenesis by bovine theca cells: influence of follicle size on responses to GDF9. Biology of Reproduction $\mathbf{7 8}$ 243-253.

Su YQ, Sugiura K, Wigglesworth K, O'Brien MJ, Affourtit JP, Pangas SA, Matzuk MM \& Eppig JJ 2008 Oocyte regulation of metabolic cooperativity between mouse cumulus cells and oocytes: BMP15 and GDF9 control cholesterol biosynthesis in cumulus cells. Development $135111-121$.

Sugiura K, Su YQ, Diaz FJ, Pangas SA, Sharma S, Wigglesworth K, O'Brien MJ, Matzuk MM, Shimasaki S \& Eppig JJ 2007 Oocyte-derived BMP15 and FGFs cooperate to promote glycolysis in cumulus cells. Development 134 2593-2603.
Teixeira Filho FL, Baracat EC, Lee TH, Suh CS, Matsui M, Chang RJ, Shimasaki S \& Erickson GF 2002 Aberrant expression of growth differentiation factor-9 in oocytes of women with polycystic ovary syndrome. Journal of Clinical Endocrinology and Metabolism 87 1337-1344.

Tomic D, Miller KP, Kenny HA, Woodruff TK, Hoyer P \& Flaws JA 2004 Ovarian follicle development requires Smad3. Molecular Endocrinology 18 2224-2240.

Vitt UA, Mazerbourg S, Klein C \& Hsueh AJ 2002 Bone morphogenetic protein receptor type II is a receptor for growth differentiation factor-9. Biology of Reproduction 67 473-480.

Yan C, Wang P, DeMayo J, DeMayo FJ, Elvin JA, Carino C, Prasad SV, Skinner SS, Dunbar BS, Dube JL et al. 2001 Synergistic roles of bone morphogenetic protein 15 and growth differentiation factor 9 in ovarian function. Molecular Endocrinology 15 854-866.

Received 2 September 2009

First decision 19 October 2009

Revised manuscript received 11 November 2009

Accepted 9 December 2009 